\title{
EDITORIAL
}

\section{Acupuncture: A Paradigm of Worldwide Cross-Cultural Communication}

\author{
XU Hao (徐 浩) ${ }^{1}$ and CHEN Ke-ji (陈可冀) ${ }^{2}$
}

On 16 November 2010, an exciting news inspired all traditional Chinese medicine (TCM) practitioners, especially acupuncturists in China. Acupuncture and moxibustion of TCM along with Peking Opera were both inscribed on the Representative List of the Intangible Cultural Heritage of Humanity during the 5th session of the United Nations Educational, Scientific and Cultural Organization (UNESCO) Intergovernmental Committee for the Safeguarding of the Intangible Cultural Heritage meeting in Nairobi. The Representative List of the Intangible Cultural Heritage of Humanity aims at ensuring better visibility of the intangible cultural heritage and raising awareness of its importance while encouraging dialogue that respects cultural diversity. The Representative List of the Intangible Cultural Heritage of Humanity now comprises 213 elements.

The term "acupuncture" comes from the Latin words "acus" (needle) and "punctura" (to puncture). It refers to the insertion of fine needles into the body at specific points for a therapeutic effect. In a broad sense, "acupuncture" in the literatures may also include moxibustion and other kinds of stimulation to certain points. In its original form, acupuncture was based on the principles of TCM, which defines good health as a balance between two complementary opposites (yin and yang) and free flow of vital force or energy (also spelt "qi", pronounced "chee") between the organs along channels (meridians), whilst in disease this flow is disrupted causing an imbalance between yin and yang. Needles inserted into specific points along the meridians provide one means of promoting the flow of qi, redressing imbalances of yin and yang, and hence treat a wide range of ailments.

The practice of acupuncture is rooted in ancient China. It is mentioned in The Yellow Emperor's Classic of Internal Medicine (Huang Di Nei Jing, 黄帝 内经), one of the oldest Chinese medical works still in existence and used today as main reference book on acupuncture theory. Acupuncture needles, dating from
4000 years ago, have been found by archeologists in China. The first needles were made from stone, and gold, silver, bronze and iron needles were used later, until stainless steel needles in modern time. Acupuncture spread into other Asian countries in about A.D. 1000, and was introduced into Europe about A.D. 1700. At the turn of last century, Sir William Osler (1849-1919), a Canadian physician, was using acupuncture to treat low back pain. Although knocked on the door of the world very early, acupuncture's recent popularity in the West dates from the 1970s, as a direct result of James Reston's famous report in the New York Times and President Nixon's visit to China.

James Reston was a reporter for the New York Times. In July 1971, he traveled to Beijing in advance of Dr. Henry Kissinger's famous trip. During his trip, Reston fell ill with appendicitis, and was treated with acupuncture following an emergency operation. Intrigued with the total relief of post-operative pain, Reston wrote of his magical experience following his return to the United States in the New York Times, sparking the mushrooming interest ${ }^{(1)}$. Reston also told Kissinger about his encounter with acupuncture, and Kissinger passed the story on to President Nixon. The President was so impressed with the story that he even visited a thyroidectomy under the condition of acupuncture anesthesia accompanied by Premier ZHOU En-lai during his traveling to Beijing in 1972. He then instituted a program in which traditional Chinese doctors came to the United States to share their medicine, and American doctors were sent to China for the same purpose. In the years following, acupuncture in the United States as well as other

(CThe Chinese Journal of Integrated Traditional and Western Medicine Press and Springer-Verlag Berlin Heidelberg 2011

1. National Integrative Medicine Center for Cardiovascular Diseases, China-Japan Friendship Hospital, Beijing (100029), China; Xiyuan Hospital, China Academy of Chinese Medical Sciences, Beijing (100091), China

Correspondence to: Prof. CHEN Ke-ji, Tel: 86-10-62860894, E-mail: chen.keji@gmail.com

DOI: 10.1007/s11655-011-0661-y 
Western countries began to take off.

According to the report of World Health Organization (WHO), acupuncture is now used in at least 78 countries and practiced not only by acupuncturists, but also by allopathic practitioners. In Belgium, $74 \%$ of acupuncture treatment is administered by allopathic doctors. In Germany, $77 \%$ of pain clinics provide acupuncture. In the United Kingdom, $46 \%$ of allopathic doctors either recommend patients for acupuncture treatment or treat their patients with acupuncture themselves. Established in 1987, the World Federation of AcupunctureMoxibustion Societies (WFAS) has nearly 60000 members from 73 acupuncture organizations from 40 countries in several regions. There are at least 50000 acupuncturists in Asia. In Europe, there are an estimated 15000 acupuncturists, including allopathic doctors who also practice as acupuncturists. The USA has 12000 licensed acupuncturists - the practice of acupuncture is legal in 38 states and six states are developing acupuncture practice policies ${ }^{(2)}$. Recently, even the New England Journal of Medicine published an article on acupuncture and low back pain ${ }^{(3)}$.

Traditional medicine (TM)/complementary and alternative medicine (CAM) therapies often develop within a very specific cultural environment, and their increasing spreading to other cultural environments is sure to raise safety and efficacy issues. As with all CAM, the absence of a formal system for reporting adverse effects means that acupuncture's safety is difficult to assess. However, it seems to be a relatively safe form of treatment with a low incidence of serious adverse events ${ }^{(2)}$. In fact, most complications in literatures are preventable not adverse events ${ }^{(4)}$. To standardize clinical practice of acupuncture, WHO has accordingly worked with experts in acupuncture to propose a standard international nomenclature in 1991 and revised it in 1993. This is now widely accepted. In addition, WHO has also developed Guideline on Basic Training and Safety in Acupuncture. These guidelines strongly encourage national health authorities to regulate acupuncture practice.

Acupuncture has been accepted by the general Chinese population as an effective curative method for a wide range of ailments. However, to be acknowledged worldwide, the East has to meet West in term of the methodology of clinical research on acupuncture and provide its efficacy and effectiveness with more evidences. Therefore, WHO developed Guidelines for Clinical Research on Acupuncture ${ }^{(5)}$. In addition, the Standards for Reporting Interventions in Clinical Trials of Acupuncture (STRICTA) reporting guidelines was first published in $2001^{(6)}$ and revised in $2010^{(7)}$. These guidelines dramatically improve the design of acupuncture clinical trial and the completeness and transparency of reporting of interventions in controlled trials of acupuncture. At the 1996 WHO conference in Milan, endorsement of acupuncture extended to 64 indications as compared with 43 indications in 1979. In 1997, the U.S. National Institutes of Health (NIH) formally recognized acupuncture as a mainstream medicine healing option with a statement documenting the procedure's safety and efficacy for treating a range of health conditions. Demonstration of other indications under investigation ${ }^{(8-10)}$ will no doubt further extend these lists.

Although a large number of randomized controlled trials have been performed, the acupuncture research has been fraught with problems and challenges all the time ${ }^{(11)}$. In this issue, Dr. Hopton and MacPherson ${ }^{(12)}$ highlight the importance of assessing blinding in randomized controlled trials to strengthen their internal validities, especially discuss challenges in clinical trials of acupuncture and provide very constructive recommendations. Dr. Witt ${ }^{(13)}$ draws on the experience from large acupuncture trials in recent years to outline the way randomized trials could be used to answer questions on efficacy and effectiveness, and also highlights the controversy over specific and non-specific effects of acupuncture emerging from the results of these trials and puts forward insightful suggestions for future clinical research on acupuncture. Dr. Lin and Chen ${ }^{(14)}$ review the present status of research on mechanism of acupuncture and moxibustion in Taiwan, especially acupuncture analgesia, which is much helpful in understanding the effectiveness of acupuncture and how it works on a scientific basis. Dr. Lee and Ernst $^{(15)}$ summarize Cochrane reviews of acupuncture for a wide range of pain conditions in recent years and provide us with an up-to-date indication list of acupuncture for pain in the principle of evidencebased medicine.

Originating in China thousands of years ago, acupuncture is not only an important part of TCM, but 
also an excellent representative of Chinese national culture. Although there are still many issues existing in respect to standardization of manipulation skill, design of clinical trials, clarification of mechanism and confirmation of safety, acupuncture has withstood the test of time, held up to the scrutiny of scientific method, and become an accepted treatment for a variety of conditions. The development and popularization of acupuncture has no doubt been a paradigm of worldwide cross-cultural communication. During this cultural integration, the East has made tremendous efforts in meeting the West. We thus sincerely call for "the West meets the East" by taking fully the traditional theory of acupuncture and meridians into consideration, and making greater reflection on the TCM pattern differentiation and complex approach. The success of TCM acupuncture in applying for being inscribed on the Representative List of the Intangible Cultural Heritage of Humanity will play an important role in protecting cultural diversity, enhancing inter-cultural dialogue and communication. Acupuncture will also, we believe, make more and more contribution to the healthcare of mankind in the future.

\section{REFERENCES}

1. Eisenberg D. Reflections on the past and future of integrative medicine from a lifelong student of the integration of Chinese and Western medicine. Chin J Integr Med 2011;17:3-5.

2. World Health Organization. Traditional medicine strategy 2002-2005. 2002. http://whqlibdoc.who.int/hq/2002/ WHO_EDM_TRM_2002.1.pdf.

3. Berman BM, Langevin HM, Witt CM, Dubner R. Acupuncture for chronic low back pain. New Engl J Med 2010;363:454-461.

4. Leung PC, Zhang L, Cheng KF. Acupuncture: Complications are preventable not adverse events. Chin J Integr Med. 2009;15:229-232.
5. Guidelines for Clinical Research on Acupuncture. Manila, WHO Regional Office for the Western Pacific, 1995 (WHO Regional Publications, Western Pacific Series No. 15).

6. MacPherson H, White A, Cummings M, Jobst K, Rose $\mathrm{K}$, Niemtzow R. Standards for reporting interventions in controlled trials of acupuncture: The STRICTA recommendations. Complement Ther Med 2001;9:246-249.

7. MacPherson $\mathrm{H}$, Altman DG, Hammerschlag R, Li $\mathrm{Y}$, Wu T, White A, et al. Revised Standards for Reporting Interventions in Clinical Trials of Acupuncture (STRICTA): extending the CONSORT statement. PLoS Med 2010; 7: e1000261.

8. World Health Organization. 2002. Acupuncture: Review and analysis of reports on controlled clinical trials. WHO Geneva.

9. Zhang CX, Qin YM, Guo BR. Clinical study on the treatment of gastroesophageal reflux by acupuncture. Chin J Integr Med 2010;16:298-303.

10. Jiang $Y H$, Jiang $W$, Jiang $L M$, Lin GX, Yang $H$, Tan $Y$, et al. Clinical efficacy of acupuncture on the morphinerelated side effects in patients undergoing spinalepidural anesthesia and analgesia. Chin J Integr Med 2010;16:71-74.

11. Kaptchuk TJ, Chen KJ, Song J. Recent clinical trials of acupuncture in the West: responses from the practitioners. Chin J Integr Med 2010;16:197-203.

12. Hopton AK, MacPherson H. Assessing blinding in randomised controlled trials of acupuncture: challenges and recommendations. Chin J Integr Med 2011;17:173-176.

13. Witt CM. Clinical research on acupuncture - concepts and guidance on efficacy and effectiveness research. Chin J Integr Med 2011;17:166-172.

14. Lin JG, Chen YH. The mechanistic studies of the acupuncture and moxibustion in Taiwan. Chin $\mathrm{J}$ Integr Med 2011;17:177-186.

15. Lee MS, Ernst E. Acupuncture for pain: an overview of Cochrane reviews. Chin J Integr Med 2011;17:187-189.

(Received January 12, 2011) Edited by ZHANG Wen 